\title{
Reducing Renal Uptake of Radiolabeled Peptides Using Albumin Fragments
}

Erik Vegt ${ }^{1}$, Julliëtte E.M. van Eerd ${ }^{1}$, Annemarie Eek $^{1}$, Wim J.G. Oyen ${ }^{1}$, Jack F.M. Wetzels ${ }^{2}$, Marion de Jong ${ }^{3}$, Frans G.M. Russel ${ }^{4}$, Rosalinde Masereeuw ${ }^{4}$, Martin Gotthardt ${ }^{1}$, and Otto C. Boerman ${ }^{1}$

${ }^{I}$ Department of Nuclear Medicine, Radboud University Nijmegen Medical Centre, Nijmegen, The Netherlands; ${ }^{2}$ Department of Nephrology and Pharmacology, Radboud University Nijmegen Medical Centre, Nijmegen, The Netherlands; ${ }^{3}$ Department of Nuclear Medicine, Erasmus University Medical Centre, Rotterdam, The Netherlands; and ${ }^{4}$ Department of Toxicology, Radboud University Nijmegen Medical Centre, Nijmegen, The Netherlands

In most types of peptide receptor radionuclide therapy, the maximum activity dose that can be administered is limited by high and persistent renal retention of the radiolabeled peptides, which is, at least partly, mediated by the megalin receptor. Several agents that interfere with renal reabsorption of radiolabeled peptides have been identified (e.g., lysine, arginine, succinylated gelatin solution), but none of these inhibit renal reabsorption completely. Albumin, a naturally abundant megalin ligand, might be a safe and potent alternative. In this study, we analyzed the effects of albumin and fragments of albumin (FRALB) on the renal reabsorption of ${ }^{111} \mathrm{In}$-diethylenetriaminepentaacetic acid (DTPA)-D-Phe ${ }^{1}$-octreotide ( ${ }^{111} \mathrm{In}$-octreotide), [ Lys $^{40}$ (aminohexoic acid-DTPA- $\left.{ }^{111} \mathrm{In}\right) \mathrm{NH}_{2}$ ]-exendin-4 ( ${ }^{111} \mathrm{In}$-exendin), and ${ }^{111} \mathrm{In}$ 1,4,7,10-tetraazacyclododecane- $N, N^{\prime}, N^{\prime \prime}, N^{\prime \prime \prime}$-tetraacetic acid (DOTA)-Glu'-minigastrin ( ${ }^{111} \mathrm{In}$-minigastrin). Methods: The effects of albumin and FRALB on megalin-associated binding of ${ }^{111} \mathrm{In}$-octreotide, ${ }^{111} \mathrm{In}$-exendin, and ${ }^{111} \mathrm{In}$-minigastrin were assessed in vitro using rat yolk sac epithelial (BN16) cells. In vivo, uptake and localization of ${ }^{111} \mathrm{In}$-albumin and ${ }^{111} \mathrm{In}$-FRALB in the kidneys of Wistar rats were determined, as well as the effect of lysine, succinylated gelatin solution, albumin, and FRALB on the kidney uptake of ${ }^{111} \mathrm{In}$-octreotide, ${ }^{111} \mathrm{In}$-exendin, and ${ }^{111} \mathrm{In}$ minigastrin. Results: FRALB significantly reduced binding and uptake of ${ }^{111} \mathrm{In}$-octreotide, ${ }^{111} \mathrm{In}$-exendin, and ${ }^{111} \mathrm{In}$-minigastrin by $\mathrm{BN} 16$ cells. In rats, renal uptake of ${ }^{111}$ In-labeled FRALB was significantly higher than that of ${ }^{111}$ In-labeled intact albumin $(P<0.001)$. FRALB administration effectively reduced renal uptake of ${ }^{111} \mathrm{In}$-octreotide, ${ }^{111} \mathrm{In}$-exendin, and ${ }^{111} \mathrm{In}$-minigastrin. Administration of 1-2 mg of FRALB reduced renal uptake of ${ }^{111}$ In-octreotide as efficiently as $80 \mathrm{mg}$ of lysine. Conclusion: Renal uptake of ${ }^{111}$ In-octreotide and other radiolabeled peptides in rats can be effectively reduced by administration of albumin fragments. Additional studies to identify the albumin fragments responsible for inhibition of renal peptide uptake are warranted.

Received Apr. 8, 2008; revision accepted May 28, 2008.

For correspondence or reprints contact: Erik Vegt, Radboud University Nijmegen Medical Centre, Department of Nuclear Medicine (444), P.O. Box 9101, 6500 HB Nijmegen, The Netherlands.

E-mail: E.Vegt@nucmed.umcn.nl

COPYRIGHT @ 2008 by the Society of Nuclear Medicine, Inc.
Key Words: renal reabsorption; octreotide; exendin; minigastrin; albumin

J Nucl Med 2008; 49:1506-1511

DOI: $10.2967 /$ jnumed.108.053249

$\mathbf{E}$ imination of radiolabeled hydrophilic peptides from the body occurs preferably via the kidneys. For scintigraphic imaging, rapid excretion of these compounds is preferable to obtain high-quality images with low background activity (1). In peptide receptor radionuclide therapy, rapid clearance of the radiolabeled peptides from the blood and low retention in the kidneys are important to minimize the radiation dose to normal tissues, especially the kidneys. However, many of these small proteins and peptides are partly retained in the kidneys because of tubular reabsorption. Renal reabsorption of (radiolabeled) peptides and proteins is a multistep process $(2,3)$. It is thought that after glomerular filtration, proteins and peptides in the ultrafiltrate bind to endocytic receptors at the luminal surface of proximal tubular cells and are internalized. Subsequently, the compounds are transferred to the lysosomes and degraded into amino acids $(2,3)$. These amino acids are transported back into the bloodstream. However, radiometal-chelated amino acids are trapped in the tubular cell lysosomes, thereby delivering high radiation doses to the kidneys $(1,4)$.

The exact mechanism of tubular reabsorption of peptides is not completely understood, but several studies have shown a role for megalin $(5,6)$. Megalin is a multiligand receptor belonging to the low-density-lipoprotein receptor family. The receptor binds various structurally different proteins (albumin, vitamin D binding protein, $\beta-2$ microglobulin, aprotinin, and many others) (5). It has been shown that some ligands bind to megalin via their cationic sites and that coadministration of basic compounds can inhibit renal reabsorption of these ligands $(6,7)$. Indeed, it has been shown in patients undergoing peptide receptor radionuclide therapy with radiolabeled octreotide, as well as in various animal models, that renal uptake of different radiolabeled peptides 
and antibody fragments can effectively be reduced by coadministration of basic amino acids such as lysine and arginine $(1,4,8,9)$. However, these compounds can cause side effects at high doses, such as nausea, hyperkalemia, arrhythmias, and even nephrotoxicity $(7,9,10)$.

Because megalin seems to play an important role in tubular reabsorption of radiolabeled peptides, we hypothesized that the megalin substrate albumin could also reduce renal uptake of radiolabeled peptides $(11,12)$. Albumin is a protein with a molecular weight of $67 \mathrm{kDa}(7)$. Only a very small fraction of total albumin passes the glomerular membrane and is reabsorbed by the renal tubular cells $(6,13-15)$.

Because only a small fraction of total intact albumin passes the glomerular membrane, we further hypothesized that fragments of albumin might be more suitable for inhibiting tubular reabsorption of peptides.

In this study, the effect of fragments of albumin (FRALB) on the renal uptake of $\left[{ }^{111} \mathrm{In}\right.$-diethylenetriaminepentaacetic acid (DTPA)-D-Phe ${ }^{1}$-octreotide ${ }^{111} \mathrm{In}$-octreotide), $\left[\mathrm{Lys}^{40}\right.$ (aminohexoic acid (Ahx)-DTPA- $\left.{ }^{111} \mathrm{In}\right) \mathrm{NH}_{2}$ ]-exendin-4 ( ${ }^{111} \mathrm{In}$ exendin), and [ ${ }^{111} \mathrm{In}-1,4,7,10$-tetraazacyclododecane- $N, N^{\prime}, N^{\prime \prime}$, $N^{\prime \prime \prime}$-tetraacetic acid (DOTA)-Glu ${ }^{1}$-minigastrin $\left({ }^{111} \mathrm{In}\right.$-minigastrin) was analyzed, both in vitro and in rats.

\section{MATERIALS AND METHODS}

\section{Albumin Fragments}

Intact albumin was fragmented by trypsin digestion. Trypsinization was performed in $50 \mathrm{mM}$ ammonium carbonate buffer, $\mathrm{pH} 7.8$, by adding $500 \mathrm{mg}$ of trypsin (Sigma) to $4.5 \mathrm{~g}$ of bovine serum albumin (Sigma) in $15 \mathrm{~mL}$ of buffer. The mixture was incubated at $37^{\circ} \mathrm{C}$ for $24 \mathrm{~h}$. The trypsinized albumin (FRALB) was analyzed by fast protein liquid chromatography (FPLC) using a Superdex 75 size exclusion column (Pharmacia). The solution of FRALB was purified using $15-\mathrm{mL}$ centrifugal filter units (Centriprep; Millipore), as outlined in Figure 1. After filtration of FRALB with a Centriprep YM-50 (50-kDa cutoff), the residue was discarded. The filtrate, containing albumin fragments with molecular weights of less than

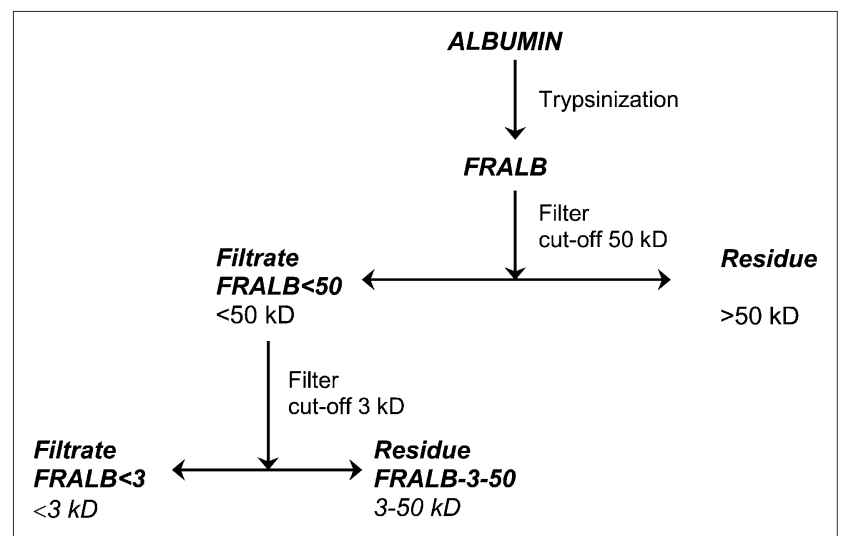

FIGURE 1. Production scheme of FRALB. Albumin was trypsinized, and resulting FRALB solution was purified via centrifugal filtration tubes to obtain solutions containing fragments with molecular weights of FRALB $<50$, FRALB-3-50, and FRALB $<3$.
$50 \mathrm{kDa}$ (FRALB $<50$ ), was further fractionated using a Centriprep YM-3 filter (3.0-kDa cutoff), producing 2 additional solutions: the filtrate containing fragments with a molecular weight of less than 3 $\mathrm{kDa}$ (FRALB $<3$ ) and the residue containing fragments with molecular weights ranging from 3 to $50 \mathrm{kDa}$ (FRALB-3-50). The protein concentration in each fraction was estimated on the basis of light absorbance at $280 \mathrm{~nm}$, as determined spectrophotometrically. The fractions were analyzed by FPLC as described above.

\section{DTPA Conjugation of Albumin and Albumin Fragments}

Albumin and FRALB-3-50 were conjugated with DTPA by incubation with a 10-fold molar excess of cDTPA (Sigma) in 0.1 M carbonate buffer, pH 9.0, as described by Hnatowich et al. (16).

\section{Radiolabeling}

[DTPA-D-Phe ${ }^{1}$ ]-octreotide (Octreoscan; Tyco) was labeled with ${ }^{111}$ In by adding $37 \mathrm{MBq}$ of ${ }^{111} \mathrm{InCl}_{3}$ to $1 \mu \mathrm{g}$ of Octreoscan and incubating for $30 \mathrm{~min}$ at room temperature.

[Lys ${ }^{40}$ (Ahx-DTPA) $\mathrm{NH}_{2}$ ]-exendin-4 (exendin) was synthesized at Peptide Specialty Laboratories $\mathrm{GmbH}$ using standard Fmoc chemistry. The peptide was labeled with ${ }^{111} \mathrm{InCl}_{3}$ in a $0.25 \mathrm{M}$ ammonium acetate buffer, $\mathrm{pH} 5.5$. A mixture of $3.7 \mathrm{MBq}$ of ${ }^{111} \mathrm{In}$ and $1 \mu \mathrm{g}$ of exendin was incubated for $30 \mathrm{~min}$ at room temperature. Subsequently, ethylenediaminetetraacetic acid was added $(12 \mu \mathrm{L}, 0.05 \mathrm{M})$ and incubated for $10 \mathrm{~min}$, after which polysorbate 80 (60 $\mu \mathrm{L}, 0.1 \%$; Sigma) was added.

[DOTA-Glu ${ }^{1}$-minigastrin (minigastrin) was synthesized at Peptide Specialty Laboratories GmbH using standard Fmoc chemistry and labeled with ${ }^{111} \mathrm{InCl}_{3}$ in a $0.25 \mathrm{M}$ ammonium acetate buffer, $\mathrm{pH} 5.5$, containing $0.6 \mathrm{~g}$ of gentisic acid per liter. $5.5 \mathrm{MBq}$ of ${ }^{111}$ In were added to $0.5 \mu \mathrm{g}(5 \mu \mathrm{L})$ of minigastrin. The mixture was incubated at $95^{\circ} \mathrm{C}$ for $25 \mathrm{~min}$.

Albumin-DTPA and FRALB-3-50-DTPA were labeled with ${ }^{111} \mathrm{InCl}_{3}$ in a $0.25 \mathrm{M}$ ammonium acetate buffer, $\mathrm{pH}$ 5.5. In a total volume of $500 \mu \mathrm{L}, 10 \mathrm{MBq}$ of ${ }^{111} \mathrm{InCl}_{3}$ were added to $200 \mu \mathrm{g}$ of albumin-DTPA or FRALB-3-50-DTPA and incubated for $30 \mathrm{~min}$ at room temperature.

Radiochemical purity and labeling efficiency of all compounds were determined by silica gel instant thin-layer chromatography and reverse-phase high-performance liquid chromatography. Radiochemical purity of all compounds was equal to or higher than $95 \%$.

\section{Compounds Used to Reduce Renal Reabsorption}

Gelofusine (Braun) is a succinylated gelatin solution $(40 \mathrm{~g} / \mathrm{L})$ $(17,18)$. Lysine solution (lysine) was prepared at a concentration of $160 \mathrm{~g} / \mathrm{L}$ in phosphate-buffered saline (PBS). Albumin and fragmented albumin (FRALB $<50$, FRALB-3-50, and FRALB $<3$ ) were prepared as described above. The molar mass of Gelofusine averages $3 \times 10^{4} \mathrm{~g} / \mathrm{mol}$ (manufacturer's data); the molar mass of FRALB $<50$ was estimated to average $1 \times 10^{4} \mathrm{~g} / \mathrm{mol}$.

\section{In Vitro Studies}

Rat yolk sac epithelial (BN16) cells expressing megalin (19) were kindly provided by Pierre J. Verroust. Cells were cultured at $37^{\circ} \mathrm{C}$ in BN16 medium consisting of Dulbecco's modified Eagle's medium plus $10 \mathrm{mM}$ glucose (Invitrogen) with $10 \%$ fetal calf serum, 100 units of penicillin per milliliter, and $100 \mu \mathrm{g}$ of streptomycin (Invitrogen) per milliliter.

The potency of FRALB to inhibit the interaction of the radiolabeled peptides with BN16 cells was compared with the potency of Gelofusine and lysine. The cells were seeded into 6 -well plates at $3 \times$ 
$10^{5}$ cells per well and cultured until confluent. The cells were washed with PBS and incubated for $1 \mathrm{~h}$ with serum-free BN16 medium, after which they were washed twice with PBS, and $2 \mathrm{~mL}$ of Ringer's solution ( $\mathrm{pH}$ 7.4) was added. Then the inhibitor was added, either lysine, Gelofusine, or FRALB $<50$ at a 100,000-fold molar excess over the radiolabeled peptide. The concentrations of the inhibitors in the medium were $7 \times 10^{4} \mathrm{~g}$ of lysine per liter, $1 \times 10^{1} \mathrm{~g}$ of Gelofusine per liter, and $3 \times 10^{2} \mathrm{~g}$ of FRALB $<50$ per liter. Directly after addition of the inhibitor, $1 \mathrm{kBq}$ of ${ }^{111}$ In-octreotide, ${ }^{111}$ In-exendin, or ${ }^{111}$ In-minigastrin was added. After $1 \mathrm{~h}$ of incubation at $37^{\circ} \mathrm{C}$, cells were rinsed once with Ringer's solution and harvested using cotton swabs. Radioactivity was measured in a shielded well-type $\gamma$-counter (Wizard; Wallac).

\section{Animal Studies}

Groups of 4 male Wistar rats (200-220 g) were used in all experiments. To investigate whether FRALB reached the proximal tubule of the kidney more efficiently than albumin, ${ }^{111}$ In-albumin and ${ }^{111}$ In-FRALB were administered intravenously to rats.

To compare the potency of FRALB to inhibit renal reabsorption of radiolabeled peptides with the potency of known inhibitors, animals were injected intravenously with $0.5 \mathrm{~mL}$ of the inhibitor (either PBS, lysine [ $80 \mathrm{mg}$ ], Gelofusine [20 mg], or FRALB $<50$ [5 mg]) via the tail vein. After $2-5 \mathrm{~min},{ }^{111} \mathrm{In}$-octreotide, ${ }^{111} \mathrm{In}$-exendin, or ${ }^{111} \mathrm{In}$ minigastrin was injected intravenously (2 MBq/rat). For ${ }^{111} \mathrm{In}-$ octreotide, a dose-response study of FRALB $<50$ was performed, and the potencies of the filtered FRALB preparations (FRALB $<50$, FRALB-3-50, and FRALB $<3$ ) were compared.

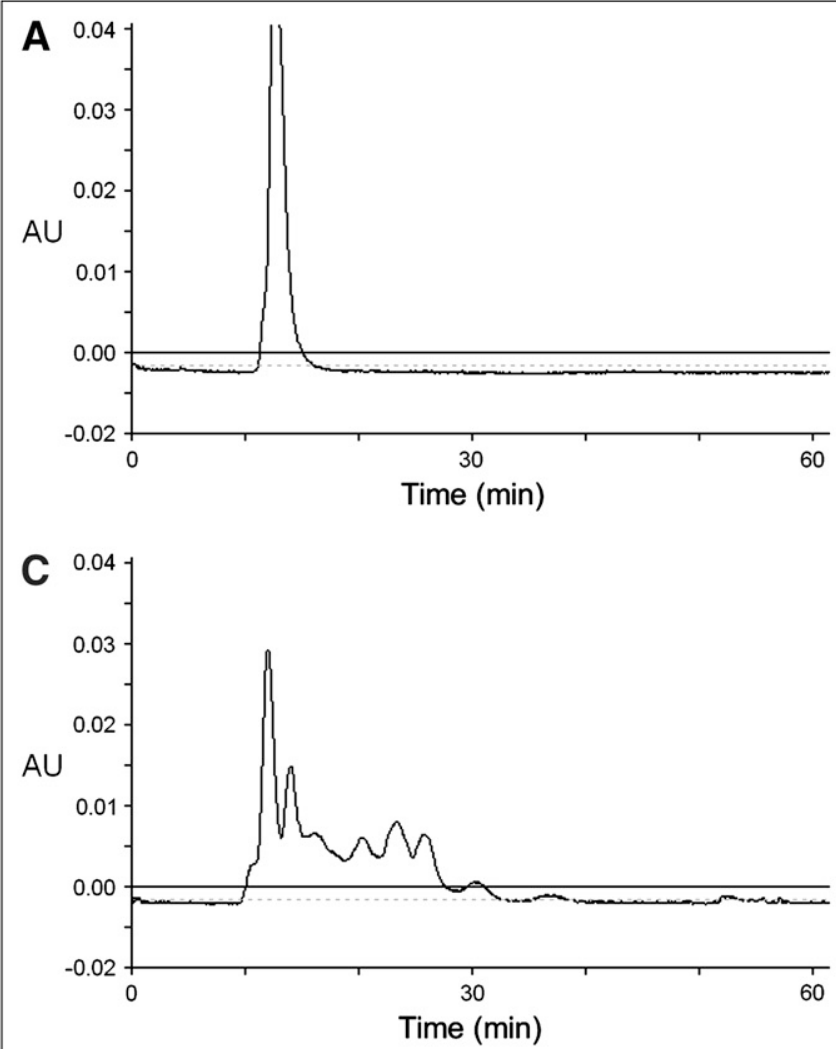

Animals were killed $20 \mathrm{~h}$ after injection, a blood sample was drawn, and organs were dissected. Tissues were weighed and counted in a shielded well-type $\gamma$-counter (Wizard) together with the injection standards. Radioactivity concentration was expressed as percentage of the injected dose per gram of tissue (\% ID/g). For autoradiography, a central 5 - $\mu \mathrm{m}$ section was cut from each kidney and mounted on poly-L-lysine-coated slides. Kidney sections were exposed to a phosphor screen overnight, which was subsequently scanned in an imaging system (Molecular Imager GS363; BioRad Laboratories) at a pixel size of $100 \times 100 \mu \mathrm{m}$.

\section{Statistical Analysis}

Data are presented as mean values \pm SD. Analysis of cell binding and kidney uptake was performed using the Student $t$ test. Biodistribution data in other organs were analyzed by 1-way ANOVA, with a correction for multiple datasets using Bonferroni's multiple comparison test. The significance level was set at 0.05 .

\section{RESULTS}

\section{Analysis of Albumin Fractions}

The FPLC elution profiles of albumin and of the 3 FRALB preparations are shown in Figure 2. Approximately 50\% of intact albumin was still present in the unpurified FRALB preparation (Fig. 2B). After ultrafiltration, FPLC analysis demonstrated that FRALB $<50$ contained less than $30 \%$ of intact albumin (Fig. 2C). In FRALB $<3$, no detectable intact albumin was present (Fig. 2D).
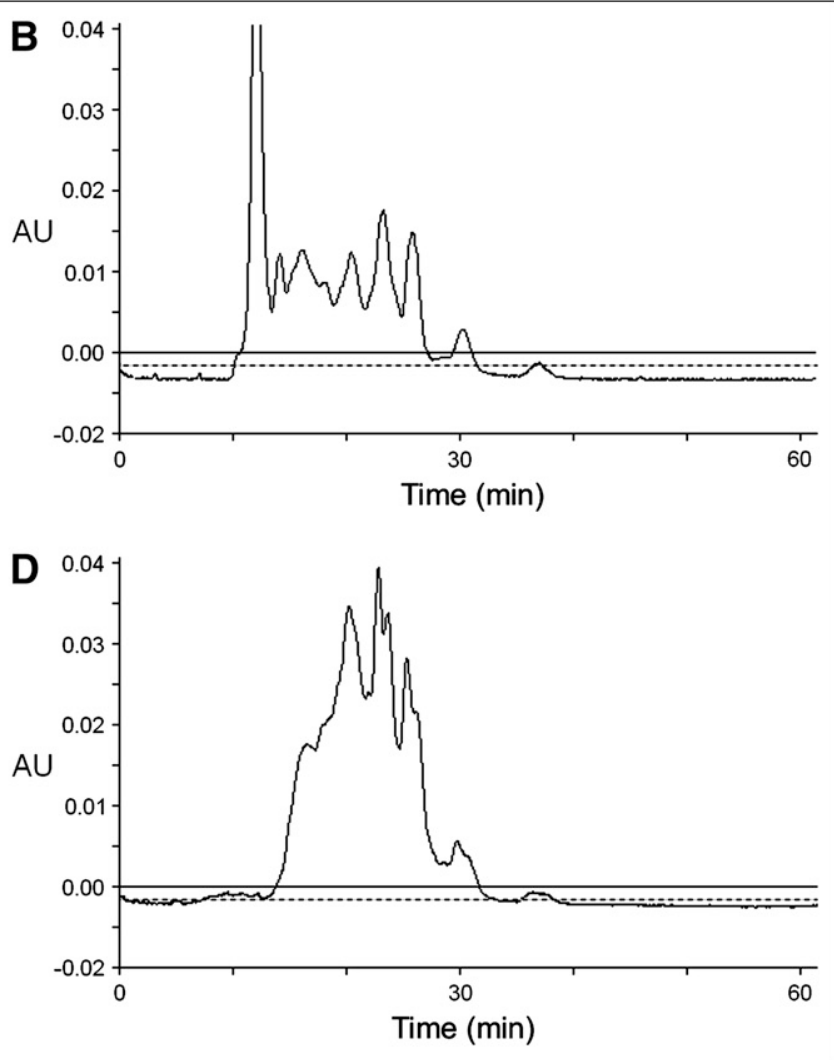

FIGURE 2. FPLC elution profile of albumin and FRALB. Analysis of $100 \mu \mathrm{g}$ of albumin (A), unpurified FRALB (B), FRALB $<50$ (C), and FRALB $<3$ (D). AU = arbitrary units. 


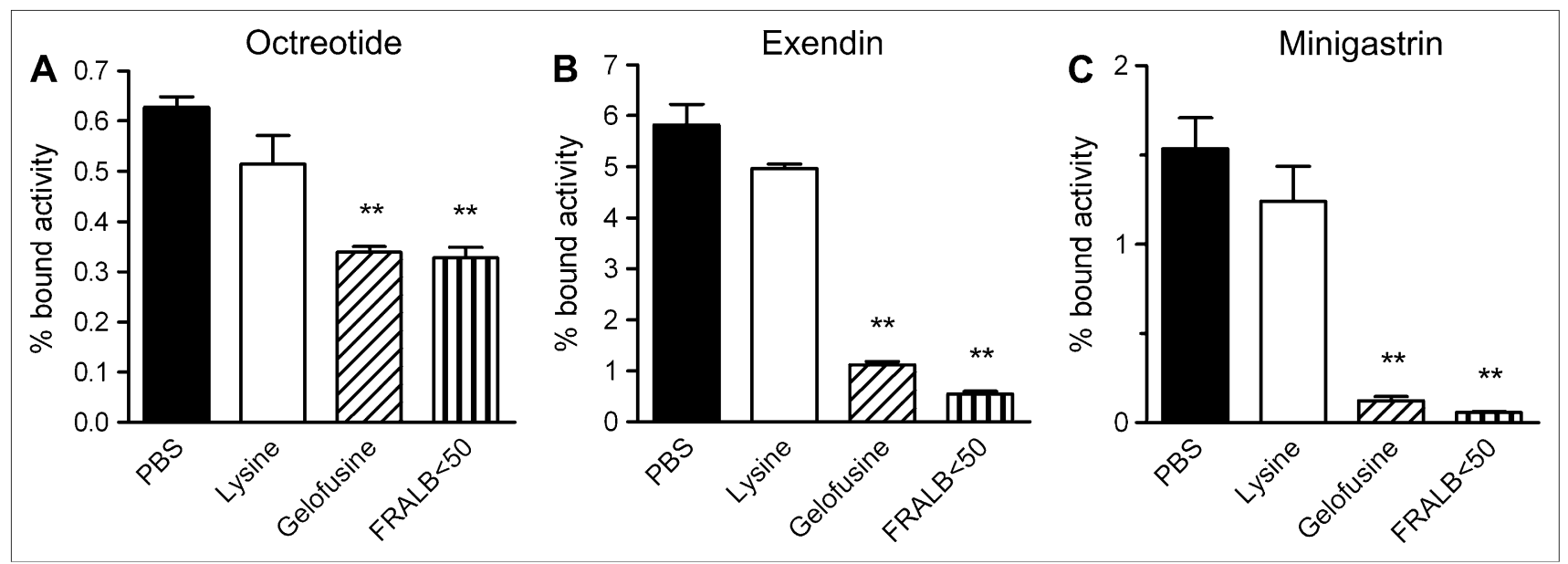

FIGURE 3. Inhibition of binding or uptake of ${ }^{111} \mathrm{In}$-octreotide (A), ${ }^{111} \mathrm{In}$-exendin (B), and ${ }^{111} \mathrm{In}$-minigastrin (C) in BN16 cells by lysine, Gelofusine, or FRALB $<50$. Results are presented as mean percentage of bound activity; error bars indicate SEM. ${ }^{\star} P<$ $0.05 ;{ }^{* *} P<0.005$.

\section{In Vitro Studies}

The BN16 assay showed that FRALB $<50$ decreased ${ }^{111}$ In-octreotide binding by $48 \% \pm 5.7 \%(P<0.001)$, as illustrated in Figure 3A. Gelofusine decreased uptake by $46 \% \pm 3.0 \%(P<0.001)$. Lysine did not significantly reduce the binding of octreotide in this assay $(P=0.14)$.

The binding of ${ }^{111} \mathrm{In}$-exendin to BN16 cells was decreased by Gelofusine and FRALB $<50$ by $81 \% \pm 1.9 \%$ $(P<0.001)$ and $91 \% \pm 1.3 \%(P<0.001)$, respectively (Fig. 3B). Lysine did not significantly reduce ${ }^{111}$ In-exendin binding $(P=0.10)$.

The binding of ${ }^{111} \mathrm{In}$-minigastrin was reduced by $96 \% \pm$ $0.5 \%$ by FRALB $(P<0.005)$ and by $92 \% \pm 2.7 \%$ by Gelofusine $(P<0.005)$ and was not decreased significantly by lysine (Fig. 3C). Higher concentrations of lysine, up to 2 $\mathrm{mg}$ (106-fold molar excess), did not reduce binding significantly either (data not shown).

\section{Biodistribution of Albumin and FRALB}

Measurement of tissue radioactivity concentration in rats $20 \mathrm{~h}$ after injection of ${ }^{111}$ In-labeled albumin or FRALB-3-50 demonstrated that kidney retention of ${ }^{111} \mathrm{In}$-albumin was significantly lower than retention of ${ }^{111}$ In-FRALB $(2.47 \pm$ $0.28 \% \mathrm{ID} / \mathrm{g}$ vs. $15.2 \pm 1.2 \% \mathrm{ID} / \mathrm{g}$, respectively; $P<0.0001$, data not shown). Furthermore, the radioactivity concentration of ${ }^{111} \mathrm{In}$-albumin in the blood was significantly higher $(0.069 \pm 0.004 \% \mathrm{ID} / \mathrm{g}$ vs. $0.011 \pm 0.002 \% \mathrm{ID} / \mathrm{g} ; P<0.0001$, data not shown), indicating faster blood clearance of the lowmolecular-weight FRALB. Phosphor imaging autoradiography of kidney sections demonstrated that, after intravenous injection of ${ }^{111} \mathrm{In}$-albumin and ${ }^{111} \mathrm{In}$-FRALB, radioactivity was present mainly in the renal cortex, as shown in Figure 4. Autoradiography also confirmed that renal radioactivity concentration of ${ }^{111}$ In-FRALB was much higher than that of ${ }^{111}$ In-albumin.

\section{Renal Uptake of Radiolabeled Peptides}

The effect of FRALB on renal uptake of ${ }^{111}$ In-octreotide is shown in Figure 5. A dose of $5 \mathrm{mg}$ of FRALB $<50$ reduced renal uptake of ${ }^{111}$ In-octreotide by $30 \% \pm 2.7 \%(P<$ 0.0001 ), which is similar to the effect of $20 \mathrm{mg}$ of Gelofusine $(32 \% \pm 7.0 \%, P<0.0001)$ and $80 \mathrm{mg}$ of lysine $(30 \% \pm$ $9.1 \%, P<0.0001)$. Doses of 1 and $0.5 \mathrm{mg}$ of FRALB $<50$ reduced uptake by, respectively, $10 \% \pm 4.6 \%(P<0.005)$ and $8.1 \% \pm 5.5 \%(P<0.05)$. The 2 other purified FRALB preparations (FRALB-3-50, $1 \mathrm{mg}$; FRALB $<3,4 \mathrm{mg}$ ) both significantly reduced renal uptake of ${ }^{111} \mathrm{In}$-octreotide $(P<$ 0.0001 ) and were as potent as $80 \mathrm{mg}$ of lysine.

Renal uptake of ${ }^{111}$ In-exendin (Fig. 6A) was reduced by FRALB $<50$ by $52 \% \pm 4.7 \%(P<0.0001)$, more potently than by either Gelofusine $(25 \% \pm 13 \%, P<0.0005)$ or lysine

\section{A}

B

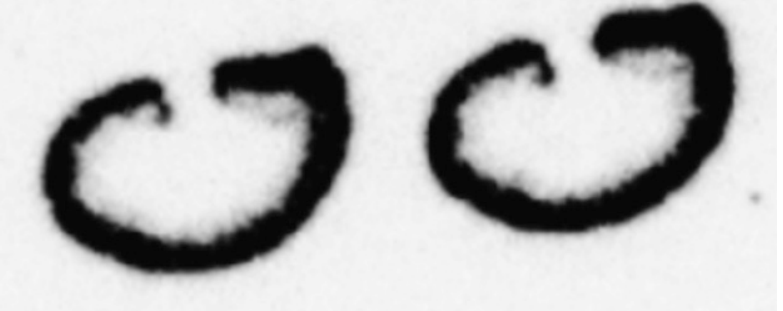

FIGURE 4. Autoradiography of renal sections of ${ }^{111} \mathrm{In}$-albumin (A) or ${ }^{111}$ In-FRALB-3-50 (B) dissected from rats, $20 \mathrm{~h}$ after injection. Radiolabeled compounds were present mainly in renal cortex. 


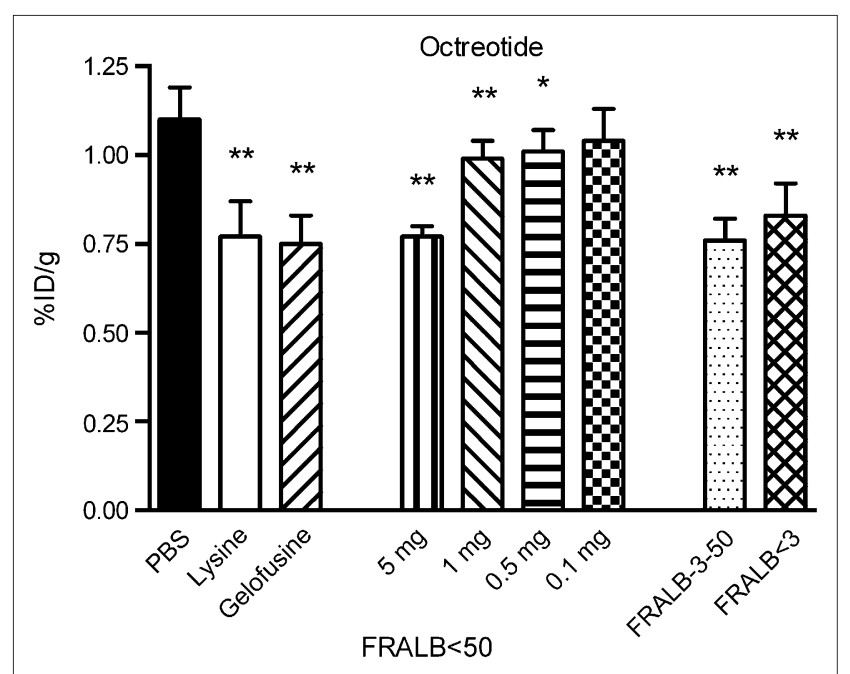

FIGURE 5. Kidney radioactivity concentrations $20 \mathrm{~h}$ after intravenous injection of ${ }^{111} \mathrm{In}$-octreotide in rats. Two to $4 \mathrm{~min}$ before injection of ${ }^{111} \mathrm{In}$-octreotide, groups of 4 rats received $0.5 \mathrm{~mL}$ of either PBS, lysine, Gelofusine, decreasing concentrations of FRALB $<50$, or different filtered preparations of FRALB. Results are presented as mean \%ID/g; error bars indicate SEM. ${ }^{\star} P<0.05 ;{ }^{\star \star} P<0.005$.

$(15 \% \pm 18 \%, P<0.05)$. Figure $6 \mathrm{~B}$ shows that renal uptake of ${ }^{111}$ In-minigastrin was almost completely blocked by FRALB $<50(93 \% \pm 0.62 \%$ reduction, $P<0.0001)$. Reduction in uptake by Gelofusine was $82 \% \pm 2.5 \%(P=0.0001)$. Lysine did not reduce uptake of minigastrin significantly.

In all experiments the FRALB did not significantly affect uptake of ${ }^{111}$ In-octreotide in tissues and organs other than the kidneys (blood, spleen, adrenals, and pancreas), as determined by ANOVA with subsequent Bonferroni testing (data not shown).

\section{DISCUSSION}

In this study, we tested the hypothesis that FRALB, a natural ligand of megalin, might be a potent inhibitor of

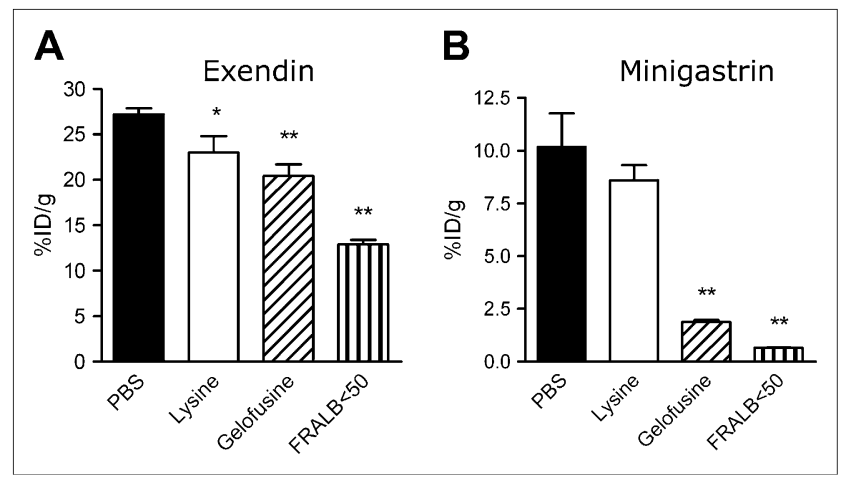

FIGURE 6. Kidney radioactivity concentrations $20 \mathrm{~h}$ after intravenous injection of ${ }^{111} \mathrm{In}$-exendin (A) or ${ }^{111} \mathrm{In}$-minigastrin (B) in rats. Two to $4 \mathrm{~min}$ before injection of radiolabeled peptide, groups of 4 rats received $0.5 \mathrm{~mL}$ of either PBS, lysine, Gelofusine, or FRALB $<50$. Results are presented as mean \%ID/g; error bars indicate SEM. ${ }^{\star} P<0.05$; ${ }^{* \star} P<0.005$. renal reabsorption of radiolabeled peptides. We hypothesized that FRALB may pass the glomerular membrane efficiently $(18,20)$ and may subsequently competitively inhibit the megalin-mediated reabsorption of these peptides.

The in vitro experiments with ${ }^{111}$ In-octreotide, ${ }^{111} \mathrm{In}$ exendin, and ${ }^{111}$ In-minigastrin showed specific binding of exendin and minigastrin to megalin-expressing cells, supporting the assumption that megalin is involved in the binding and uptake of these peptides. However, a contribution of other mechanisms of uptake cannot be excluded. Relatively small amounts of FRALB inhibited binding of ${ }^{111} \mathrm{In}$-octreotide, ${ }^{111} \mathrm{In}$-exendin, and ${ }^{111} \mathrm{In}$-minigastrin to the BN16 cells at least as efficiently as Gelofusine. Remarkably, in vitro lysine did not reduce binding significantly.

The biodistribution studies of ${ }^{111}$ In-DTPA-albumin and ${ }^{111}$ In-DTPA-FRALB in rats support the hypothesis that FRALB passes the glomerular membrane more efficiently than does intact albumin. The renal activity concentration of FRALB was more than 5-fold higher than the concentration of intact albumin. Both albumin and FRALB were retained mainly in the renal cortex, the same anatomic location in which previous studies showed localization of ${ }^{111}$ In-octreotide, ${ }^{111}$ In-exendin, ${ }^{111}$ In-minigastrin, and megalin (21-24).

In our experiments in rats, coadministration of FRALB effectively reduced renal uptake of ${ }^{111}$ In-octreotide, presumably because of interaction of the albumin fragments with the megalin receptor in the kidneys. Barone et al. demonstrated that uptake of ${ }^{111}$ In-octreotide by opossum kidney cells was, at least partly, mediated by endocytosis via the megalin/ cubilin receptor complex (25). The most convincing evidence was reported by de Jong et al., who showed that renal uptake of ${ }^{111} \mathrm{In}$-octreotide was very low in kidney-specific megalin knock-out mice (21) and that ${ }^{111}$ In-octreotide colocalized with megalin staining on murine kidney sections $(21,22)$.

FRALB significantly reduced renal radioactivity concentrations of ${ }^{111} \mathrm{In}$-octreotide in a concentration-dependent manner. Fragments with a molecular weight between 3 and 50 $\mathrm{kDa}$ appeared to be most potent. Injection of as little as $1 \mathrm{mg}$ of FRALB-3-50 per rat resulted in the same reduction in renal ${ }^{111}$ In-octreotide concentration as the administration of $20 \mathrm{mg}$ of Gelofusine or $80 \mathrm{mg}$ of lysine.

Gelofusine and FRALB efficiently reduced renal uptake of all studied peptides, whereas a high dose of $80 \mathrm{mg}$ of lysine did not decrease uptake of ${ }^{111}$ In-minigastrin significantly. This confirms our previous hypothesis that inhibition of tubular reabsorption of radiolabeled peptides such as octreotide by basic amino acids may be the exception rather than the rule for radiopeptides (23).

The megalin receptor possesses 4 distinct negatively charged binding domains (26). This may explain why renal reuptake of some substances is blocked by lysine, whereas reuptake of other substances is not. Lysine and octreotide may interact with the same binding domain, whereas exendin and minigastrin may bind to 1 or more other domains. One or more components of FRALB and Gelofusine, consisting of various different smaller and larger molecules of different 
structure and charge, may interact with 2 or more of the binding domains of megalin, thus efficiently blocking renal reabsorption of various substances.

An alternative explanation could be that renal uptake of ${ }^{111} \mathrm{In}$-exendin and ${ }^{111} \mathrm{In}$-minigastrin is not inhibited by lysine, because uptake of these radiolabeled peptides may be mediated by mechanisms other than the megalin receptor. Whereas renal uptake of ${ }^{111}$ In-octreotide has been shown to be, at least partially, mediated by megalin $(21,22)$, the role of megalin in uptake of exendin and minigastrin is not yet established. Our group (23) and Melis et al. (24) have previously suggested the possible involvement of various different uptake mechanisms in the tubular reabsorption of radiolabeled peptides, such as organic anion transporters, cubilin, and fluid-phase endocytosis. We are currently conducting further studies into the mechanisms of renal reuptake of these radiolabeled peptides.

The effect of FRALB on the reduction of renal reabsorption of ${ }^{111} \mathrm{In}$-octreotide, ${ }^{111} \mathrm{In}$-exendin, and ${ }^{111} \mathrm{In}$-minigastrin in this study was equal to or more pronounced than the effects of either Gelofusine or lysine. On a mass basis, the administered dose of FRALB that induced this effect was 5-20 times lower than the Gelofusine dose and 16-80 times lower than the lysine dose. Using FRALB, more potent inhibition of uptake may be achievable with less chance of side effects. However, although intact albumin is not toxic under physiologic conditions, albumin-derived peptides could be toxic as they have physical and chemical characteristics different from those of albumin. Unlike albumin, these peptides can reach relatively high concentrations in the glomerular filtrate on intravenous injection. Obviously, toxicity studies of FRALB must be performed before it can safely be used in patients.

The FRALB used in these studies, obtained by trypsinization of albumin, contains a poorly defined mixture of many different albumin fragments. To identify the most potent inhibitor of renal reuptake of radiolabeled peptides and to minimize the chance of unwanted side effects, further studies are warranted to purify FRALB and to further clarify its mechanism of action.

\section{CONCLUSION}

Renal uptake of ${ }^{111} \mathrm{In}$-octreotide, ${ }^{111} \mathrm{In}$-minigastrin, and ${ }^{111}$ In-exendin is effectively reduced by administration of relatively low amounts of FRALB. The administration of $1 \mathrm{mg}$ of FRALB with a molecular weight between 3 and 50 $\mathrm{kDa}$ was as effective in reducing the renal uptake of ${ }^{111} \mathrm{In}$ octreotide as an administration of $80 \mathrm{mg}$ of lysine. Further studies will be performed to identify which specific albumin fragments are responsible for this effect.

\section{ACKNOWLEDGMENTS}

We thank Gerry Grutters, Maarten Brom, and Bianca Lemmers (University of Nijmegen, Central Animal Laboratory) for their expert technical assistance in the animal experiments.

\section{REFERENCES}

1. Behr TM, Goldenberg DM, Becker W. Reducing the renal uptake of radiolabeled antibody fragments and peptides for diagnosis and therapy: present status, future prospects and limitations. Eur J Nucl Med. 1998;25:201-212.

2. Silbernagl S. The renal handling of amino acids and oligopeptides. Physiol Rev. 1988;68:911-1007.

3. Christensen EI, Gburek J. Protein reabsorption in renal proximal tubulefunction and dysfunction in kidney pathophysiology. Pediatr Nephrol. 2004; 19:714-721.

4. de Jong M, Rolleman EJ, Bernard BF, et al. Inhibition of renal uptake of indium111-DTPA-octreotide in vivo. J Nucl Med. 1996;37:1388-1392.

5. Christensen EI, Birn H, Verroust P, Moestrup SK. Megalin-mediated endocytosis in renal proximal tubule. Ren Fail. 1998;20:191-199.

6. Mogensen CE, Sølling K. Studies on renal tubular protein reabsorption: partial and near complete inhibition by certain amino acids. Scand J Clin Lab Invest. 1977;37:477-486.

7. Rolleman EJ, Valkema R, De JM, Kooij PP, Krenning EP. Safe and effective inhibition of renal uptake of radiolabelled octreotide by a combination of lysine and arginine. Eur J Nucl Med Mol Imaging. 2003;30:9-15.

8. Thelle K, Christensen EI, Vorum H, Orskov H, Birn H. Characterization of proteinuria and tubular protein uptake in a new model of oral L-lysine administration in rats. Kidney Int. 2006;69:1333-1340.

9. Pimm MV, Gribben SJ. Prevention of renal tubule re-absorption of radiometal (indium-111) labelled Fab fragment of a monoclonal antibody in mice by systemic administration of lysine. Eur J Nucl Med. 1994;21:663-665.

10. Bernard BF, Krenning EP, Breeman WA, et al. D-lysine reduction of indium-111 octreotide and yttrium-90 octreotide renal uptake. J Nucl Med. 1997;38:19291933.

11. Christensen EI, Birn H. Megalin and cubilin: multifunctional endocytic receptors. Nat Rev Mol Cell Biol. 2002;3:256-266.

12. Moestrup SK, Cui S, Vorum H, et al. Evidence that epithelial glycoprotein 330/ megalin mediates uptake of polybasic drugs. J Clin Invest. 1995;96:14041413.

13. Birn H, Christensen EI. Renal albumin absorption in physiology and pathology. Kidney Int. 2006;69:440-449.

14. Farquhar MG. The glomerular basement membrane: not gone, just forgotten. J Clin Invest. 2006;116:2090-2093.

15. Gekle M. Renal tubule albumin transport. Annu Rev Physiol. 2005;67:573-594.

16. Hnatowich DJ, Childs RL, Lanteigne D, et al. The preparation of DTPA-coupled antibodies radiolabeled with metallic radionuclides: an improved method. J Immunol Methods. 1983;65:147-157.

17. van Eerd JEM, Vegt E, Wetzels JFM, et al. Gelatin-based plasma expander effectively reduces renal uptake of ${ }^{111} \mathrm{In}$-octreotide in mice and rats. $\mathrm{J} \mathrm{Nucl} \mathrm{Med}$. 2006;47:528-533.

18. Vegt E, Wetzels JF, Russel FG, et al. Renal uptake of radiolabeled octreotide in human subjects is efficiently inhibited by succinylated gelatin. J Nucl Med. 2006;47:432-436.

19. Le Panse $S$, Verroust $P$, Christensen EI. Internalization and recycling of glycoprotein 280 in BN/MSV yolk sac epithelial cells: a model system of relevance to receptor-mediated endocytosis in the renal proximal tubule. Exp Nephrol. 1997;5:375-383.

20. Tencer J, Frick IM, Oquist BW, Alm P, Rippe B. Size-selectivity of the glomerular barrier to high molecular weight proteins: upper size limitations of shunt pathways. Kidney Int. 1998;53:709-715.

21. de Jong M, Barone R, Krenning EP, et al. Megalin is essential for renal proximal tubule reabsorption of ${ }^{111}$ In-DTPA-octreotide. J Nucl Med. 2005;46:16961700 .

22. Melis M, Krenning EP, Bernard BF, Barone R, Visser TJ, de Jong M. Localisation and mechanism of retention of radiolabelled somatostatin analogs. Eur J Nucl Med Mol Imaging. 2005;32:1136-1143.

23. Gotthardt M, van Eerd-Vismale J, Oyen WJ, et al. Indication for different mechanisms of kidney uptake of radiolabeled peptides. J Nucl Med. 2007; 48:596-601.

24. Melis M, Krenning EP, Bernard BF, de Visser M, Rolleman E, de Jong M. Renal uptake and retention of radiolabeled somatostatin, bombesin, neurotensin, minigastrin and CCK analogues: species and gender differences. Nucl Med Biol. 2007;34:633-641.

25. Barone R, Van Der Smissen P, Devuyst O, et al. Endocytosis of the somatostatin analogue, octreotide, by the proximal tubule-derived opossum kidney (OK) cell line. Kidney Int. 2005;67:969-976.

26. Orlando RA, Exner M, Czekay RP, et al. Identification of the second cluster of ligand-binding repeats in megalin as a site for receptor-ligand interactions. Proc Natl Acad Sci USA. 1997;94:2368-2373. 